\title{
Research on Aesthetical Principles in Solfeggio Teaching
}

\author{
Ying Liang
}

Ningxia Institute of Science and Technology, Shizuishan, 753000, China

\author{
Keywords: Solfeggio teaching, Aesthetic principles, Research
}

\begin{abstract}
The music has aesthetic property; therefore, in music learning, the students shall not only perfect themselves in professional music knowledge and improve professional skills, but also pay attention to cultivating musical emotion and getting a deep understanding of music style and musical artistic state, which can help students to improve their music skills and music culture. Through discussion on aesthetic elements of solfeggio teaching, this paper summarizes the aesthetical principles in solfeggio teaching and then effectively improve students' music learning effect and promote the development of music art.
\end{abstract}

\section{Introduction}

In recent years, with gradually deepening of modern education system, the learning of music art gradually shows its important value. The music has certain aesthetic feature; it not only can improve students' music accomplishment and artistic culture, but also can deepen students' cultural deposits and promote students comprehensive healthy development. As a basic course of music learning, the solfeggio can help students to learn intonation, rhythm, mode and other musical elements of music; besides, it can improve students' psychological cognition on music, effectively combine theory with practice, cultivate students' musical aesthetic ability, and then improve their skill learning effect to certain degree.

\section{Aesthetic factor of solfeggio}

The solfeggio teaching is the basis of music learning, and also the cultivation to students' music accomplishment. The solfeggio is a music learning process from simplicity to complexity, and it starts from learning of tone, intonation and other musical elements and then gradually penetrates into learning of emotion and style of musical culture. In this learning process, the students can improve their aesthetic ability via learning music knowledge. Therefore, as a kind of unique music learning course, the solfeggio has certain aesthetic factor from internal and external perspective.

\section{Aesthetic property of solfeggio}

\section{Aesthetic feeling of intonation and tone}

The intonation and tone of music are basic aesthetic property of music learning, and they reflect the basic aesthetic feeling of music to certain degree. The tone is just the feature of sound. In learning process, it is required to actively establish scientific concept of aesthetic feeling of tone and carry out learning via solfeggio method. Except for learning basic music knowledge, the students shall also actively seek for the tone beauty of music. Therefore, in sight-singing process, it is required to ensure the quality of tone and gradually cultivate musical aesthetic ability.

\section{Aesthetic feeling of rhythm and melody}

The aesthetic feeling of rhythm and melody is another property of music aesthetics. The aesthetic feeling of rhythm is the aesthetic feeling of music formed in the change of rhythm and frequency of music. The rhythm in aesthetic feeling of rhythm is the most basic beauty of rhythm, and the rhythmic pattern is the backbone of aesthetic feeling of rhythm. Besides, the plate type in aesthetic feeling of rhythm is also an important factor which enhances music characteristics. 
The melody belongs to an basic element of musical teaching, and its position is also very important; it is an important way of musical expression. Therefore, in the solfeggio learning, we shall continuously enhance the experience and discovery on aesthetic feeling of melody to improve our musical infection and musical imagination.

\section{Aesthetic feeling of style and structure}

The aesthetic feeling of style and structure belongs to the highest level of musical aesthetic property, and the complete and perfect musical structure is an important part of beautiful music. Therefore, if the overall structure of music is more complicated, it will be more difficult for people to appreciate it. As for this, we can improve the ability of understanding music via solfeggio learning method.

The aesthetic feeling of musical style is the specific expression of musical culture. The music originates from life; different countries and regions have different cultures, thus their musical style and feature are also different. In Chinese music, due to the difference in era and territory, multiple musical styles are formed. Therefore, we shall continuously taste and understand different styles of music in the solfeggio learning process.

\section{Improving aesthetic skills of solfeggio}

Based on the aesthetic skills of solfeggio, it is able to effectively improve aesthetic skills of solfeggio, get a deep perception and understanding of music, and enjoy the aesthetic feeling of music brought to people. In the solfeggio training process, it is required to make the sound and performance of musical instrument balanced, and carry out perfect combination of sound and tone so as to realize beautiful sound effect. Besides, the scientific nature of solfeggio shall be effectively mastered. The musical expression shall be accurately made from scientific perspective; in this process, it is required to pay attention to delivery of aesthetic feeling of music, cultivate students' consolidated consciousness of rhythm and intonation, and improve students' aesthetic analysis ability.

The solfeggio is specific art of music in which the aesthetic elements are penetrated; therefore, mastering its aesthetic property is of certain positive significance for improving aesthetic skills.

\section{Aesthetic environment principle in solfeggio teaching}

In the solfeggio learning process, the music is students' aesthetic object, and the teacher plays a main guiding role. As the subject of solfeggio teaching activity, the students shall actively carry out discussion and research with teachers on teaching of musical aesthetics, and positively express their opinions and ideas to aesthetic feeling of music. The aesthetic value of music is the core of all contents. As a kind of specific aesthetic experience form, the solfeggio can help students to cultivate aesthetic consciousness and learn aesthetic concepts.

In the process of establishing aesthetic principle, the teachers play a great function, for the teachers' behaviors will cause certain influence and guidance function on students. In the aesthetic teaching of solfeggio, the teachers mainly take teaching concept, form, content, and way of classroom as starting point to bring students into musical context in unconscious teaching process, and then motivate students' musical aesthetic learning and desire; meanwhile, in the teaching process, the teachers shall emphasize students' learning state and consciousness, and require students to restrain themselves via aesthetic concept. Except that, the teaching environment of solfeggio also causes certain influence on students' musical aesthetic learning, thus it is able to help to shape students' aesthetic mood and cultivate students' consciousness of aesthetic environment through effectively improving the teaching environment of solfeggio. The aesthetic is students' reaction on musical aesthetics and it is established on students' thoughts and consciousness. Therefore, while students take the training and learning of professional musical knowledge and skills, they shall carry out reasonable imagination based on realistic scene, and combine with their own aesthetic mood to carry out effective understanding and experience of music. In the solfeggio learning process, the students shall keep gentle and rational state, which can help them to effectively appreciate the tone of music 
and obtain their own musical experience. Besides, the students shall strictly follow teachers' guidance and requirement, regulate their mood at any time, realize the regulation and control on themselves upon experiencing the aesthetic feeling of music, and effectively combine aesthetic mood with external aesthetic environment so as to obtain rational learning and perceptual experience of aesthetic feeling of music, which also fully shows the importance of aesthetic environment principle on musical learning in the solfeggio teaching process.

\section{Aesthetic desire principle in solfeggio teaching}

The aesthetic desire of music is the emotional judgment on musical aesthetics. In the actual teaching of solfeggio, the teachers' guidance has important influence on students' perception and feeling of musical aesthetics. Therefore, in the solfeggio teaching, the teachers shall always keep teaching consciousness of musical aesthetics and carry out effective teaching and correct guidance on students based on certain teaching purpose, as well as fully exert teachers' teaching ability and teaching level.

As the subject who guides students to carry out musical aesthetics, the teachers shall have certain ability of musical distinguishing and aesthetics, and make use of their own ability to mobilize students' enthusiasm in learning of musical aesthetics, and motivate students' learning desire so that the students can carry out understanding and perception of musical language according to teachers' correct guidance direction.

The students' aesthetic perception in musical learning not only starts from their own aesthetic desire, but also depends on teachers' professional musical knowledge. In the actual music classroom teaching, the teachers' proficient musical performance skills can effectively promote students' emotion of musical learning, make students exert their imagination to their heart's content, motivate students' desire of musical aesthetics, and then activate the learning atmosphere of music classroom. Besides, in the practice of musical vision and aesthetics, the students' interaction with teachers and other students can make the musical art atmosphere in classroom become more harmonious and strong. The teachers can also carry out detailed analysis on difficult points in students' learning process through explanation on musical theoretical knowledge so that the students can continuously improve their aesthetic cognition ability of music and realize effective circle of musical learning.

\section{Aesthetic experience and creation principle in solfeggio teaching}

The aesthetic feeling of music is obtained by listeners through scene imagination on musical content and their own psychological experience; therefore, in the solfeggio learning, the students shall pay attention to their own experience of musical aesthetics. The aesthetic activity of music starts from aesthetic feeling, and then the listeners bring themselves into the artistic conception of music through aesthetic imagination and experience of music together with change of different emotion. Except that, the solfeggio teaching not only requires students' aesthetic imagination, but also requires the guidance and motivation of objective and actual information source so as to cause continuous change in students' inner emotion and bring students into aesthetic experience of music through combination with objective reality and subjective imagination. This kind of aesthetic representation originates from life and exceeds beyond life. In the process of observation and perceiving on actual life, we shall perfectly combine ourselves with musical scene, and then realize aesthetic experience via long-time accumulation and cognition. While the teachers carry out solfeggio teaching, they shall not only fully utilize materials, but also carry out objective and actual delivery to impart effective and accurate musical information to students. As for classroom teaching content with complicated and difficult content, the teachers shall mark out the key and difficult points before class, make prompts at any time, and require students to carry out repeated practice in classroom learning process so as to realize proficient degree and effect.

The aesthetic creation of solfeggio is an inner creation process of carrying out super-aesthetic things together with the experience of musical aesthetics. Through effectively combining life practice 
with aesthetic experience of music, we can obtain aesthetic imagination and then perceive the important significance of aesthetic creation. The aesthetic creation is students' improvement and creation on music, and also the re-creation on original music based on imagination and expansion. In the solfeggio teaching, the teachers can adopt teaching means of imago materialization to cultivate students' creation ability of musical aesthetics. While the students listen to music, it is able to make them fully experience the scene in musical content and carry out reasonable imagination on musical style so that the students can gradually step into the imagination of imago from musical appreciation, enter into sight-singing link, and realize the true purpose of imago materialization. Furthermore, in the classroom teaching of musical solfeggio, the students can actively participate in classroom review, which not only can expand students' thinking, but also can effectively promote the interaction between teachers and students, improve the relationship between teachers and students, and then realize the aesthetic creation of musical teaching.

\section{Aesthetic cognition principle in solfeggio teaching}

As is known to us, the musical solfeggio teaching involves rich aesthetic factors and aesthetic resources. Therefore, in the teaching process, the teachers shall actively and effectively discover the perception and cognition efficiency contained in teaching link, carry out corresponding extraction, summarize the key points of perception and cognition, and then carry out targeted training to realize the teaching purpose.

The musical teaching mainly focus on cultivating students' ability to master musical skills and skillfully apply the music. The cultivation of this kind of ability shall be made on the basis of multiple knowledge, and the solfeggio teaching way is an effective means to cultivate this comprehensive ability. In the lesson preparation before class, the teachers shall do well in structural analysis of classroom teaching content and classroom teaching steps, and seize students' psychological expectation in classroom learning and effective way of before-class introduction so as to seize students' aesthetic vision as much as possible.

While the teachers carry out training of sight-singing skills for students, they shall adopt effective training method to ensure that the students can have stable attitude, stable rhythm, and stable sense of rhythm in learning process, and also suitably control the accuracy in regulation and rhythm. Besides, the teachers shall carry out the training of complete musical structure and complete layer, melody, and style for students so that the students can effectively find out the perception points in training process.

As for musical learning, different students have different understanding ability and perception ability; in the solfeggio teaching process, the most important thing is the inspiration on music. In order to improve students' comprehension ability and inspiration ability on music, the teachers shall take easy teaching content as start point, and summarize key and difficult points in classroom teaching. According to students' different advantages and features, the teachers shall carry out flexible teaching, seek for the best means through which it is able to make students improve cognition and inspiration within short time, guide students to use correct learning way, promote students' cognition ability of musical aesthetics, and improve students’ musical learning effect.

\section{Conclusion}

The solfeggio teaching plays an important role in musical teaching; it is also a basic course for students to learn music and lays a steady foundation for students' deep musical learning. With the reform and deepening of education system, the musical education gradually shows its shining points in students' learning system. In musical teaching, the learning of solfeggio course cultivates students' music accomplishment, and improves students' musical cognition and inspiration ability. Through strictly following the aesthetic principles in solfeggio teaching, it is able to gradually master the skills of musical learning and improve ways and methods of musical learning under the assistance of 
solfeggio course, improve teachers' professional level, motivate students' learning desire, and also promote students' musical learning as well as promote the healthy development of musical education.

\section{References}

[1] Yang Yang, Ruan Xiaoqin, Discussion on Aesthetic Principles in Solfeggio Teaching, Youth Literator, 2013 (20).

[2] Song Yang: Discussion on Aesthetic Property of Solfeggio, Popular Art, 2013 (8).

[3] Zhan Chun, Discussion on Aesthetic Methods in Solfeggio Teaching, Notonly Music, 2014 (17).

[4] Yang Sanchuan, Analysis on Aesthetic Principles in Solfeggio Teaching, Notonly Music, 2013 (17).

[5] Chen Yuan, Discussion on Reflection of Aesthetic Value in Solfeggio Teaching, Hunan Normal University, 2013. 